\title{
APLICABILIDADE DO EYE TRACKING EM TESTES DE USABILIDADE DE APLICATIVOS DE SMARTPHONE
}

Jessé Cerqueira | Bolsista de Iniciação Científica

LEUI | Laboratório de Ergodesign e Usabilidade de Interfaces - PUC-Rio

jolivcerq@gmail.com

Pedro Coelho | Bolsista de Iniciação Científica

LEUI | Laboratório de Ergodesign e Usabilidade de Interfaces - PUC-Rio cabralcoelho@gmail.com

Patrícia Carrion | Mestranda

LEUI | Laboratório de Ergodesign e Usabilidade de Interfaces - PUC-Rio patriciac@aluno.puc-rio.br

Rafael Cirino Gonçalves | Mestrando

LEUI | Laboratório de Ergodesign e Usabilidade de Interfaces - PUC-Rio rafaelcirinogoncalves@gmail.br

Manuela Quaresma, D.Sc.

LEUI | Laboratório de Ergodesign e Usabilidade de Interfaces - PUC-Rio mquaresma@puc-rio.br

Resumo: Cada vez mais, novas tecnologias têm revolucionado o campo da usabilidade, trazendo novas formas de análise para testes na área. Alguns dos principais exemplos no mercado são o EEG (eletroencefalograma), simuladores de alta fidelidade e, principalmente, dispositivos de eye tracking. Este último funciona a partir de uma câmera infravermelha que permite o rastreamento do olhar do usuário em relação ao que ele está olhando, seja um objeto ou uma interface, possibilitando assim análises sobre o direcionamento do olhar e atenção do usuário frente a diferentes estímulos visuais. Apesar de suas vantagens, existem inúmeros fatores no uso da tecnologia de eye tracking que podem interferir na consistência da realização dos testes e dados captados. Visto que tais fatores nem sempre são abordados na literatura, este artigo objetiva discorrer sobre potenciais de aplicação e barreiras operacionais deste dispositivo, que vão desde o momento do recrutamento dos participantes até a análise dos dados obtidos. Com base nas experiências adquiridas durante uma série de testes de usabilidade no contexto de interfaces mobile, foram elencadas as principais considerações quanto ao uso da tecnologia de eye tracking (com base no aparelho Tobii X2-60), ponderando suas vantagens, limitações e apontando meios de otimizar a aplicação desses dispositivos em pesquisas. Como conclusão, foram detectadas vantagens e desvantagens no uso da ferramenta ao longo do processo. Nos melhores cenários, o nível de precisão dos registros do dispositivo é muito alto, permitindo uma 
compreensão eficaz do uso de interfaces e isenta das impressões subjetivas do participante. Além disso, os dados captados pelo dispositivo podem ser analisados através de numerosas possibilidades de métricas e cruzamentos de dados, tais como a concentração e a movimentação do olhar, reincidência do olhar em determinadas áreas e o tempo de realização da tarefa. Em contrapartida, é necessário satisfazer a exigências técnicas do equipamento como: filtragem dos participantes com características específicas (uso de óculos bifocal, pessoas com cílios grandes, portadores de doenças visuais como glaucoma, etc.); realização de procedimentos de calibragem para adequar o aparelho às especificidades dos olhos de cada usuário; aprendizado sobre o programa usado para análise, suas funções e limitações. A boa consistência dos dados coletados pelo dispositivo depende, em grande parte, de ensaios sobre o processo de mediação e da atenção ao funcionamento do dispositivo e às configurações específicas pertinentes à realização do teste. Devem ser observados, principalmente, questões referentes ao posicionamento do dispositivo e suas partes, a manutenção da postura dos participantes e a não-obstrução da peça responsável pela captura do olhar, podendo ser determinantes para garantir a fidelidade das informações captadas. No que tange ao software do próprio Eye tracker, é necessária atenção a possíveis problemas técnicos e respeitar certos parâmetros durante a realização dos testes para que os dados registrados estejam adequados às ferramentas de análise disponíveis. Como explicitado, o emprego dessa tecnologia em testes de usabilidade oferece benefícios expressivos, mas requer um alto grau de preparação e entendimento a respeito das especificidades e limitações estruturais e funcionais envolvidas na sua utilização.

Palavras-chave: Teste de Usabilidade, Eye tracking, Aplicativos de Smartphone 